\title{
A Teoria dos Blocos Semânticos em revisão
}

\section{The Theory of Semantic Blocks in review}

\section{Julio Cesar Machado}

Universidade do Estado de Minas Gerais, Passos, Minas Gerais / Brasil julio.semantica@gmail.com

Resumo: A Teoria dos Blocos Semânticos ocupa lugar significativo nos trabalhos em Semântica, Argumentação e Enunciação, entre outros, em todo o mundo. Por isso sua pertinência para a Linguística reclama uma reflexão profunda. O presente trabalho analisa algumas reformulações feitas nessa teoria nas últimas duas décadas, a saber: (a) polifonia, (b) bloco semântico, e (c) quadrado argumentativo. Especificamente, trata das seguintes relações: (a') da Teoria Polifônica da Enunciação à Teoria Argumentativa da Polifonia; (b') do bloco semântico ao quase-bloco; e (c') do quadrado argumentativo ao cubo argumentativo. A necessidade deste trabalho é duplamente justificada: (i) devido à constante revisão teórica do arcabouço deste saber, sobretudo na sua última década, característica de Marion Carel e de Oswald Ducrot; e (ii) pela falta de tradução/circulação no Brasil de obras fundamentais no que tange à reelaboração das noções chaves desta teoria.

Palavras-chave: polifonia; quase-bloco; cubo argumentativo.

Abstract: The Theory of Semantic Blocks occupies an internationally significant place in Semantics, Argumentation and Enunciation, among other fields. Therefore, its relevance to Linguistics should lead to some reflection. This study intends to evaluate some reformulations in the Theory of Semantic blocks that have taken place in the past two decades, namely on the following concepts: (a) polyphony, (b) Semantic block, and (c) argumentative square. Specifically, this paper approaches the 
following relationships: (a') from the Polyphonic Theory of Enunciation to the Argumentative Theory of Polyphony; (b') from the Semantic Block to the Semi-block; and (c') from the argumentative square to the argumentative cube. The necessity for the reported research results is doubly justified given: (i) the constant theoretical review of this approach framework, especially in the last decade, by Marion Carel and Oswald Ducrot; and (ii) the lack of translations and widespread knowledge in Brazil of fundamental reference pieces dealing with the re-elaboration of key concepts in this theory.

Keywords: polyphony; quasi-bloc; argumentative cube.

Recebido em: 20 de maio de 2016.

Aprovado em: 22 de agosto de 2016.

\section{Introdução ${ }^{1}$}

A Teoria dos Blocos Semânticos (TBS) consolidou-se nos estudos enunciativos e argumentativos, em Linguística, enquanto fase mais radical $^{2}$ dos estudos sobre argumentação na língua, que apresenta eco de

\footnotetext{
${ }^{1}$ Este artigo é uma ampliação e aprofundamento de uma discussão proposta, de modo resumido, no $3^{\circ}$ Seminário Internacional de Estudos sobre Discurso e Argumentação - III Sediar, em 2016, na Universidade Federal do Sergipe, em São Cristóvão/SE.

2 "Radical" no que se entende por fidelidade à (interpretação da) obra póstuma saussureana do Cours de Linguistique Générale. Quando um linguista diz "fidelidade à (uma interpretação de) Saussure" é importante dizer algumas palavras sobre tais interpretações de Saussure no Brasil, haja vista os caminhos que alguns teóricos podem atribuir (ou subtrair) à Teoria dos Blocos Semânticos. Ressalvamos que há, grosso modo, no mínimo duas interpretações básicas desta obra póstuma, no Brasil - dentre muitas interpretações - que nos interessa aqui, e que vamos explicar da seguinte forma, para melhor ilustrá-las: (1) uma primeira interpretação que desconsidera várias releituras e movimentos no arcabouço do Estruturalismo, presentes, por exemplo, na obra Écrits de linguistique générale, obviamente justificada pela sua tardia e recente publicação em 2002 na França (uma antiga interpretação estrutural, que opera por exclusão). Esta primeira interpretação trata-se de uma leitura mais difundida em manuais de semântica brasileiros, onde estudar a língua por ela mesma "já foi" aceitar uma condição de privar-se de uma série de outras questões próprias da língua, balizando-se por um
} 
quase 50 anos de trabalho, identificado pelo nome amplo de Semântica Argumentativa. Este artigo quer refletir sobre o arcabouço teórico que constitui este saber nas suas últimas duas décadas. Deste modo, este artigo tem por objetivo geral: apresentar e discutir alguns dos momentos mais significativos de reformulações no quadro teórico da TBS, desde o seu surgimento até a atualidade, adotando um critério que privilegie textos de Ducrot e Carel no histórico das últimas duas décadas (especificamente de 1992 a 2016). E para cumprir este propósito, escolheremos textos destes dois autores que desenvolvem reformulações significativamente drásticas na relação com elaborações anteriores.

\section{Ler a TBS}

A eleição da temática deste artigo tem dupla justificativa. Primeiro, a TBS ainda é uma teoria inacaba, está ainda (e sempre) em período de metarreflexão, como Carel admitiu para nós (CAREL; MACHADO, 2016, p. 45): "nós estamos todo o tempo doutorando, deslocando, reformulando nossas teses". E isso põe uma questão: como estudar e operar uma teoria em constante revisão? Neste caso, uma teoria

receio de não estar mais estudando a língua, mas qualquer outra coisa fora dela; e (2) uma segunda interpretação de Saussure que propõe e considera várias (re)leituras e movimentos excluídos outrora, na primeira interpretação, presentes, por exemplo, na mesma obra dos Écrits (uma jovem interpretação estrutural, que opera por inclusão). Esta segunda interpretação, re-leitura de Saussure, significa, no Brasil, uma interpretação menos difundida, e basicamente recente, onde estudar a língua é flagrar, nela e por ela, todo seu impacto significável, tanto "somente-intra-língua" (primeira interpretação, delimitativa) como "extra-língua-possível-via-intra-língua" (segunda interpretação, ampliativa), já que, conforme a segunda interpretação, não há exterior sem interior (ora, se algo exterior à língua é significado, aludido, conclamado, sugerido, relacionado ou atribuído a uma estrutura de língua, já houve necessariamente o movimento de tocar na estrutura, pressuposicionalmente falando, em maior ou menor grau, lexicalmente ou enunciativamente). Esta acuidade de fidelidade à (interpretação de) Saussure ainda persiste na TBS, mas, principalmente, e cada vez mais, depois do final dos anos 90, por vias desta segunda interpretação, inclusiva. O leitor atento percebe que a TBS opera de modo mais profundo e refinado ao notar a sofisticação de seus teóricos ao trabalharem questões contemporâneas da Linguística como texto (CAREL, 2009; 2011b), discurso (CAREL, 2011a, 2011b; CAREL; DUCROT, 2015) e anterioridades argumentativas (CAREL, DUCROT, 1999a; CAREL, 2011a, 2011b e 2016), por exemplo. Não excluindo questões, mas as refletindo por vias da própria TBS e seus critérios. 
em constante revisão implica um pesquisador da TBS disciplinado, no seguinte sentido: o leitor da TBS já sabe que a constante revisão teórica é estilo de Oswald Ducrot e Marion Carel. Ela está sempre presente nos seus trabalhos, o que acarreta dizer que o semanticista ou linguista que tenha interesse na TBS deve se disciplinar em estudos constantes de atualização (textos recentes), tradução (textos que só circulam na França ${ }^{3}$ ), e leituras por pares (versão atualizada+versão anterior), para produzir uma sintonia satisfatória entre conhecimentos e procedimentos exigidos pela TBS e as preocupações da Linguística, do Estruturalismo Enunciativo, da Semântica e especificamente dos estudos enunciativos da Argumentação.

Ler a TBS não significa pretender gestos de condensação ou esgotamento enciclopédico de todo seu acervo, já que sua metodologia não é quantitativa. Significa, antes, estar pelo menos ciente de suas hipóteses gerais e igualmente ciente de seus constantes reajustes, reformulações, re-elaborações de duas décadas (gesto mais próximo de um leitor recente da TBS) até percepções avançadas do arcabouço técnico da TBS, que significa poder realizar macro-revisões críticas processadas no ritmo da dinâmica analítica desta teoria nos últimos 40 anos (gesto mais próprio de um leitor profundo da TBS).

Obviamente tais leituras da TBS demandam uma discussão constante entre a TBS, textos anteriores, questões institucionais, questões de recepção acadêmica, e discussões próprias das ideias linguísticas hodiernas, além de um intenso contato com grupos de pesquisas franceses e brasileiros que discutem, elaboram e utilizam tal teoria, sobretudo com o grupo de Marion Carel e Oswald Ducrot, na École des Hautes Études en Sciences Sociales (Escola de Altos Estudos em Ciências Sociais), em Paris, na França, e outros que se atentam para a obra de seus fundadores, com rigor de estudo e pesquisa, como os trabalhos da Dra. Leci Borges Barbisan, no Brasil, Dra. María Marta García Negroni, na Argentina, e Dr. Alfredo Lescano, na França, por exemplo, dentre outros.

A segunda justificativa da escolha temática deste artigo põe relevo sobre o problema da inacessibilidade no ocidente de alguns textos chaves

\footnotetext{
${ }^{3}$ Neste sentido, queremos destacar aqui, dentre outros, o trabalho intenso e de excelência da Dra. Leci Borges Barbisan, que supre bem esta lacuna da inviabilização de textos da TBS no Brasil. A linguista merece destaque pelas constantes traduções fiéis, e por isso confiáveis, da TBS para leitores brasileiros não-leitores de francês.
} 
para se acompanhar, entender e melhor saber operar a TBS. Trata-se não apenas de um problema de tradução, mas de veiculação. Especificamente, quatro obras deixam lacunas singulares de não-tradução para o português (e por isso ocasionando desconhecimento das mesmas no Brasil) e nãoveiculação no Brasil, impactando fortes lacunas na recepção e consideração da TBS para a Linguística Brasileira: o livro "La Sémantica Argumentativa: una introducción a la Teoría de los Bloques Semánticos" (CAREL; DUCROT, 2005), que merece destaque por apresentar a radicalização dos trabalhos sobre argumentação na língua nos moldes da TBS, e pela significativa exposição introdutória da totalidade das principais noções da TBS; O livro "L'entrelacement Argumentatif" (O entrelaçamento argumentativo) (CAREL, 2011a), que reflete uma revisão detalhada e profunda da TBS, com propostas de continuidade e reformulações da polifonia, e atualizações de análises clássicas como as do pressuposto e do "mas", por exemplo; Textos como "Le quase-bloque" (o quase-bloco) (CAREL; DUCROT, 2015), oriundo das aulas de Carel e Ducrot em Paris, entre os anos de 2013 a 2016, e "Présupposition et organisation du sens" (pressuposição e organização do sentido) (CAREL, 2016), que tratam ambos dos principais pontos de discussões oriundas dos trabalhos atuais (entre os anos de 2013 a 2016) sobre os chamados quase-blocos e a revisão dos clássicos pressupostos, dentre outras noções.

A desconsideração de textos como estes, para o semanticista da TBS, dá gravidade de inadequação para tratar de certos conceitos teóricos, como as noções de frase, enunciação, doxa, paradoxo, polifonia, enunciador, pessoa, bloco semântico, atitude discursiva, cubo argumentativo e o conectivo "mas" (noções estas trabalhadas adiante), dentre outros, ou torna inadequada ou defeituosa a operação da TBS no que tange à análise de certos objetos, como o texto ou a poesia, ou ainda produz inadequação teórica ao tentar forjar adequações de textos clássicos de Ducrot dos anos setenta a noções atuais, desconhecendo suas já totalmente reformulações na última década, principalmente.

Este quadro de objetivos e justificativas acima retrata bem a emergência de se discutir (o processo de evolução teórica da) TBS nos diversos espaços científicos da linguagem que fazem uso da TBS, com suas determinâncias. 


\section{Observando uma teoria: fases e reformulações}

É difícil, senão impossível, expandir a dinâmica da evolução de um saber sem the seccionar sua multiplicidade constitutiva. Obviamente a discussão seccional é sempre polêmica: por exemplo, há quem diga que a Semântica Argumentativa está divida em três fases: standard, Topoï e Blocos, há quem diga que Ducrot (usa-se este nome, o que já se explicita um equívoco pela nomenclatura) divide-se em quatro ou menos fases, $o$ próprio Ducrot se diz dividido em fases, existem as muitas organizações de divisão para se lecionar a TBS, dentre tantas outras tentativas de se observar o compasso e mensura tangente que determina qualquer autonomia epistemológica, e aqui, a TBS.

Sem entrar no mérito da divisibilidade das fases, sempre atitudes de locutores, queremos neste trabalho marcar alguns momentos teóricos em conformidade com nossos objetivos, deixando várias discussões interessantes de lado, evidentemente, mas acentuando a adoção de um critério de pertinência de mudanças significativamente drásticas no histórico dos últimos 24 anos da TBS, que vemos abaixo.

\section{Fase de construção}

Esta fase se desenvolve basicamente na primeira década de idade do novo formato da Semântica Argumentativa, por blocos semânticos, conforme corroboram certas publicações, das quais destacamos a Tese de concepção inicial da TBS, de sua própria autora, não traduzida no Brasil: "Vers une formalisation de la théorie de "l'argumentation dans la langue" (Em direção a uma formalização da teoria da "argumentação na língua") (CAREL, 1992) - acatada por Ducrot, mas não de imediato - que previa a re-adequação, radicalização e aprofundamento dos trabalhos sobre argumentação na língua. É nesta fase que também se destaca a já citada obra de significativa exposição introdutória das principais noções da TBS, e também não traduzida no Brasil: "La Sémantica Argumentativa" (CAREL; DUCROT, 2005). Finalmente, elencam esta fase, inúmeros outros artigos que lograram êxito na construção e na solidez do novo molde formal dos trabalhos em argumentação na língua. A maioria destes artigos foram traduzidos graças à duas revistas brasileiras que merecem destaque por estarem sempre atentas à tradução e acompanhamento do desenrolar dos trabalhos da TBS: a revista Letras de Hoje, da PUCRS, e a revista Desenredo, da Universidade de Passo Fundo. 
Estes primeiros quinze anos, principalmente a primeira década, cumpriram um papel importante de produção científica que produziu efeitos de ilustratividade das noções e sumarização teórica: é a fase da consolidação epistemológica da TBS. Obviamente que a construção deste saber, nesta primeira década, discorreu através da elaboração de dezenas de artigos e outras publicações que no momento não nos é pertinente expor. O que retemos é que a totalidade das publicações da TBS na primeira década, aproximadamente, vão no sentido de consolidar seu arcabouço teórico através da exploração analítica de uma multiplicidade de objetos analisados, e em detrimento da necessidade de se difundir este construto teórico pelo mundo, notadamente na Europa e na América Latina.

Basicamente, esta fase constrói a grande hipótese e lema da TBS: todo enunciado é parafraseável por um encadeamento do tipo normativo (portanto) ou do tipo transgressivo (no entanto) (CAREL; DUCROT, 2014, p. 78). Por exemplo, como explica Ducrot (2009, p. 22), analisar semanticamente a expressão "depressa demais" é observar sua relação com a expressão "risco de sofrer acidente". A relação entre estas duas expressões é um aspecto argumentativo: [DEPRESSA DEMAIS PORTANTO RISCO DE SOFRER ACIDENTE]. E todo aspecto impõe uma decisão semântica: se a relação entre expressões for realizada pelo conector portanto, ela é chamada de argumentação normativa. Obviamente toda norma prevê sua transgressão, e se caso a significação entre as duas expressões seja o oposto da normativa, será ilustrada por no entanto e será chamada de argumentação transgressiva. Acima, ao se pensar a expressão "depressa demais" na relação com "não sofrer acidente", produz-se um movimento semântico transgressivo, ilustrado pelo aspecto: [DEPRESSA DEMAIS NO ENTANTO NEG-RISCO DE SOFRER ACIDENTE].

Assim, a radicalidade da TBS que se buscou consolidar nesta fase advém da hipótese da interdependência: toda palavra instaura relação, e relação argumentativa: em uma relação entre duas palavras " $\mathrm{X}$ conector Y”, a significância é a inseparabilidade entre essas duas palavras.

\section{Fase da revisão}

Esta fase, que corresponde aproximadamente à segunda década de existência da TBS, é marcada por uma intensa revisão técnico-teórica, das quais destacamos as discussões sobre (a) polifonia, (b) bloco semântico, 
e (c) quadrado semântico (dentre outras tantas revisões que o espaço não nos permite expor). Passemos a estas discussões.

\subsection{Da Teoria Polifônica da Enunciação à Teoria Argumentativa da Polifonia (TAP)}

Por volta de 2009, Carel e Ducrot publicam textos propondo substituir a antiga Teoria Polifônica da Enunciação (DUCROT, 1984) pela Teoria Argumentativa da Polifonia, TAP (CAREL, DUCROT, 2010; CAREL, 2009; 2011a; 2011b), que se deu gradativamente, em três momentos, conforme a autora:

No primeiro, em Dire et ne pas dire (Dizer e não dizer) (DUCROT, 1972), apresentar um conteúdo se reduzia a tomar uma atitude diante do conteúdo (e não havia a noção de enunciador);

No segundo, em Le dire et le dit (o dizer e o dito) (DUCROT, 1984), antes de se tomar uma atitude diante de certo conteúdo, mostram-se os enunciadores que tomam essas atitudes (e não há a noção de atitude).

No terceiro, em L'Entrelacement argumentatif(CAREL, 2011a), dentre outras obras, muda-se a natureza da atitude (agora discursiva, e dividida em três), muda-se a natureza e a dinâmica do enunciador (agora integrante do conteúdo e não fora dele), e muda-se a dinâmica de alguns pressupostos (podendo ser interdependente com o posto, eliminando certas polifonias).

Para exemplificar, tomemos o enunciado clássico:

\section{(1) Pedro parou de fumar.}

Exemplificando (I), diremos que diante do tradicional (1) o locutor toma uma atitude de reconhecer um conteúdo [Pedro fumava] e toma uma atitude de assumir esse conteúdo [Pedro não fuma atualmente].

Exemplificando (II), diremos que há dois enunciadores em (1): o ponto de vista E1 [Pedro fumava] e o ponto de vista E2 - [Pedro não fuma atualmente]. O locutor (outro personagem) poderia assimilar um ou outro, dependendo da situação. Um terceiro personagem seria atribuído para identificar Pedro, o $\lambda$.

Exemplificando (III), diremos que o encadeamento (1) expressa o único conteúdo interdependente posto pelo locutor [Pedro-parou-defumar-NO ENTANTO-ele-fumava-antes] em que não há polifonia - no sentido antigo, da Teoria Polifônica da Enunciação, de Ducrot (1984) -, 
já que o que temos no enunciado é uma passagem entre estados [fumavaantes-e-agora-não-fuma], e não dois estados: [fumava antes] e [agora não fuma]. Tanto enunciador como $\lambda$ não existem mais (são substituídos pela noção de Pessoa, que veremos). O exemplo de (III) não significa que não há polifonia para a TBS, senão que o enunciador mudou de estatuto. $\mathrm{O}$ modo de apreender e operar o exemplo acima é a marca determinante da Teoria Argumentativa da Polifonia.

\subsubsection{Da atitude clássica à atitude discursiva}

Mais especificamente, atualmente, na TAP, fica mantida a significação observável pela polifonia à luz das seguintes noções chaves: conteúdo, atitude do locutor e Pessoa do discurso (CAREL; DUCROT, 2010 , p. 15). No que tange ao conteúdo, ele ainda é aquilo que é dito (CAREL, 2011a, p. 355), mas agora, pela TBS, passará a ser observado a partir de aspectos e encadeamentos (em DC e PT). ${ }^{4}$ Carel (2011a, p. 329) isola dois fenômenos significáveis independentes do conteúdo, que constituirão duas diferenças básicas entre a TAP e a antiga Teoria Polifônica da Enunciação, de Ducrot (CAREL, 2011a, p. 298): a atitude discursiva (antiga atitude) e a Pessoa (antigo enunciador).

Carel e Ducrot (2010, p. 15) convencionarão três atitudes discursivas, ou concepção triádica da polifonia: por, concordar e excluir (um conteúdo). Por exemplo (CAREL, 2011a, p. 305):

(2) Pedro não é bonito. Ao contrário, ele é feio.

Formalmente, a fórmula deste enunciado é “ $X$ é $P$ ”. Discursivamente, imaginemos duas situações para ilustrar as atitudes discursivas. Na primeira delas, X é P seria uma afirmação séria (no sentido de sem ironia). Como se alguém enunciasse isso ao olhar para uma foto de alguém extremamente hórrido para os padrões doxais dos manequins universais, e expressasse sua impressão. A TAP vai dizer que o locutor exclui o conteúdo [Pedro é bonito], e põe o conteúdo OPP ${ }^{5}$ [Pedro é bonito] (ou: põe [Pedro é feio]).

\footnotetext{
${ }^{4}$ Notação basal da TBS:

$\mathrm{DC}=$ portanto $($ do francês donc $)$;

$\mathrm{PT}=$ no entanto (do francês pourtant).

${ }^{5}$ OPP significa "oposto".
} 
Por outro lado, num discurso oposto, num dado caso em que tal enunciado (2) fosse enunciado em uma situação em que alguém, diante de um manequim extremamente esplêndido e suntuoso, que lhe causasse a impressão de falta de palavras, e na falta dessas enunciasse (2), ironicamente, neste caso X é P seria uma afirmação não-séria (no sentido de "com ironia"). Nesta última situação, a TAP vai dizer que a ironia é tal que o locutor exclui [Pedro é feio] ao enunciar Pedro é feio, e vai por [Pedro é bonito] ao enunciar Pedro não é bonito.

\subsubsection{Da pressuposição à atitude de concordar}

No total, há três atitudes discursivas por, excluir (já vistas), e concordar. Para ilustrar a atitude de concordar, tomemos:

(3) O muro do jardim estava coberto de trepadeira.

Neste enunciado, Carel (2011a, p. 301) vai dizer que o locutor apresenta dois julgamentos: [o muro estava coberto de trepadeira] e [o jardim tinha um muro]. O semanticista deverá decidir para quê o locutor tomou a palavra: se para falar da trepadeira, ou para falar do muro do jardim. Supondo que o locutor tomou a palavra para falar da trepadeira (o que ali, vagamente e descontextualizado, parece o mais óbvio), a TAP dirá que o locutor concorda que [o jardim tinha um muro] e põe [o muro estava coberto de trepadeira]. Não é difícil de perceber na atitude discursiva de concordar uma forte alusão à noção do antigo pressuposto.

Carel diz que o concordar jamais é uma atitude isolada. Não se pode concordar com um conteúdo sem por um outro (do mesmo modo que não se pode excluir um conteúdo sem por um outro), o que instaura uma sempre relação concordar/por de um lado e excluir/por de outro: "a teoria da enunciação que eu utilizarei deverá assim permitir atribuir três atitudes discursivas ao locutor de um enunciado: as duas atitudes positivas 'concordar' e 'por', e a atitude negativa 'excluir'" (CAREL, 2011a, p. 308).

\subsubsection{Do enunciador externo ao conteúdo ao enunciador integrado ao conteúdo}

Comparativamente com a fase de construção, diremos que surge aqui a problematização da noção técnica de enunciador. Até então 
existiam basicamente duas instâncias da polifonia, que mantinham naturezas diferentes, mas coexistiam: o locutor e o enunciador. "Se o locutor é, na maior parte do tempo, único, há geralmente vários enunciadores relacionados com vários conteúdos" (CAREL; DUCROT, 2010, p. 10). Na reformulação da TAP, os enunciadores não constituem mais seres individuais que representam a origem dos pontos de vista, mas tipos de seres que refletem modos, abstrações e asserções. Consideremos um exemplo de Carel e Ducrot (2010, p. 17):

(4) Segundo o crítico do Monde, o último filme de Woody Allen fracassou totalmente.

Nas elaborações anteriores da Teoria polifônica da Enunciação, o enunciador era uma personagem, que acima seria o crítico do Le Monde, que dava seu "ponto de vista", o fracasso do filme. Mas Carel e Ducrot vêem nessa metodologia uma incoerência com a TBS: "Não se pode sustentar que o sentido seja puramente argumentativo, e ao mesmo tempo, admitir que a expressão o crítico do Monde designa um ser que [...] teria um 'ponto de vista' sobre os filmes que vê"' (CAREL; DUCROT, 2010, p. 17). Os linguistas vão dizer que este enunciado não significa o que significa por conta de uma entidade que não integra propriamente o enunciado (o enunciador: o crítico do Monde).

$\mathrm{Na}$ TAP, fase de revisão teórico-polifônica, o sentido deste enunciado acima é que o último Woody Allen não-agradou-ao-críticodo-Monde, ou formalmente, [POUCO ORIGINAL DC FRACASSOU] (CAREL; DUCROT, 2010, p. 18). Fica claro que, pela TAP, abandona-se o olhar de origem do enunciador da segunda elaboração de Ducrot (1984): "uma tal apreensão da palavra será descrita não por uma 'unidade de discurso' cujo enunciador seria $\mathrm{X}$ e o conteúdo seria $[p]$, mas por uma 'unidade de discurso' cujo conteúdo é [X transmitiu p]' (CAREL, 2011a, p. 330).

Em suma, a ideia de enunciador não se trata mais de origem nem de ponto de vista: "não pode se tratar de ângulo de vista, pois nós o incluímos no interior do conteúdo" (CAREL; DUCROT, 2010, p. 18). $\mathrm{O}$ enunciador não pode ser absorvido nas três atitude discursivas (por, concordar e excluir), mas ao contrário, o enunciador deve ser integrado ao conteúdo (CAREL; DUCROT, 2010, p. 18). 


\subsubsection{Do enunciador à Pessoa do discurso}

Uma vez que "o que importa semanticamente não é a identidade individual dos enunciadores [...] mas o modo particular pelo qual eles preenchem o papel geral que lhes é conferido" (CAREL; DUCROT, 2010, p. 19), Carel e Ducrot proporão que a antiga ideia de enunciador seja coerentemente atualizada por uma noção que represente esta nuance enunciativa, a Pessoa.

A noção de Pessoa prevê cinco vozes: L, TU, NÓS, MUNDO, e ELE. Completa-se, assim, o cerne da re-elaboração polifônica: três atitudes (por, concordar e excluir) e suas cinco Pessoas, que se dinamizam pelos conectores DC e PT.

Especificamente, conforme a proposta de Carel (2011a, p. 331), as pessoas representam a voz que o locutor toma. O locutor pode assim fazer entender:

i. Pela sua própria voz de locutor (L), marcada por “eu”, por exemplo, como em: "O cigarro é ruim para mim";

ii. Pela voz de interlocutor (TU), marcada por um "você", por exemplo, como em: " $O$ doutor me disse que o cigarro é ruim para mim";

iii. Pela voz coletiva, ou de opinião pública (NÓS), marcada por "nós", por exemplo, como em "As pessoas da área da saúde sempre afirmam que fumar é ruim";

iv. Pela voz mais forte do senso comum, da "verdade" construída, dos fatos que se impõem (MUNDO), sem marcas estruturais específicas, como em "Fumar é prejudicial à saúde";

v. Pela paradoxal voz da ausência, um certo (ELE). A voz afastada, da ausência, sem autoridade, marcada por "parece que", por exemplo, como em: "Parece que o cigarro não faz bem a você", que põe $[q]$ com a voz de ELE.

Nesta fase de re-elaboração nota-se que o termo técnico pessoas vislumbra seres míticos-enunciativos: "Elas se distinguem dos ângulos de vista pelo fato de que elas não relativizam o conteúdo comunicado. Elas participam apenas da apresentação dos conteúdos" (CAREL, 2011a, p. 340). 


\subsubsection{Do enunciador-conteúdo à unidade discursiva}

Analiticamente, ao se aplicar o par polifônico destas duas noções: atitudes discursivas (por, concordar, excluir) e pessoas do discurso (L, TU, NÓS, MUNDO, ELE), tem-se a unidade discursiva. Consideremos o enunciado:

(5) O tempo está bom.

Formalmente, teríamos a seguinte fórmula e sua aplicação:

Unidade discursiva: (posto, MUNDO, [O tempo está bom])

Carel (2011a, p. 339) pondera que o sentido da unidade acima seria algo como o encadeamento: "você concorda, portanto, que é um tempo para fazer piquenique, não?" que exprimiria a AE à direita de "tempo bom": [TEMPO BOM DC FAZER PIQUENIQUE]. Tecnicamente falando, na fórmula preenchida de (5), observamos a noção teórica de unidade discursiva: o conjunto que entrelaça uma atitude discursiva (por, concordar ou excluir), uma pessoa (L, TU, NÓS, MUNDO, e ELE) e um conteúdo mobilizado pelo enunciado (entre colchetes [ ]).

Agora acrescentemos muito na mesma enunciação. Teríamos:

(5') O tempo está muito bom.

Formalmente, teríamos a seguinte fórmula e sua aplicação (já que muito é uma marca do L):

Unidade discursiva: (posto, L, [O tempo está bom]).

Carel (2011a, p. 339) explica que o sentido da unidade (5') seria algo como o encadeamento: "Nós vamos, portanto, aproveitar desse tempo propício para piquenique para fazer um piquenique, não?" que exprimiria: [TEMPO DE PIQUENIQUE DC FAZER PIQUENIQUE].

Ainda uma terceira reformulação. Acrescentemos parece que no mesmo enunciado. Teríamos:

(5") Parece que o tempo está bom.

Formalmente, teríamos a seguinte fórmula e sua aplicação:

Unidade: (posto, ELE, [O tempo está bom]) 
Carel (2011a, p. 341) entende (5") como de uma maneira de apresentar [o tempo está bom] aumentado de um comentário: "só esse conteúdo é introduzido. O conteúdo [alguém disse que o tempo está bom] não é nem posto nem concordado. Ele é totalmente ausente do enunciado". Os valores do enunciado (encadeamento e aspecto) seriam basicamente os mesmos de (5).

Ainda poderíamos simular outro funcionamento:

(5"') Vejo que o tempo não está bom.

Cuja fórmula e aplicação seriam, simultaneamente:

Unidade i): (excluído, L, [o tempo está bom]) e

Unidade ii): (posto, L, OPP [o tempo está bom]).

No que tange à atitude discursiva de concordar, retomemos o exemplo (3) acima: O muro do jardim estava coberto de trepadeira. Cujas unidades podemos apresentar agora:

Unidade i): (concordado, L, [o jardim tinha um muro])

Unidade ii): (posto, L, [o muro estava coberto de trepadeira])

\subsection{Do bloco ao quase-bloco}

Como vimos, o grande lema e suma da TBS, na primeira década, sua fase de construção teórica, foi: todo enunciado é parafraseável por aspectos em DC e PT. Já na fase de revisão, Carel e Ducrot perceberam que há certas palavras/significações cujo aspecto só é melhor expresso de modo intermediário, algo como a soma entre normativo (DC) + transgressivo (PT). É uma fase laboratorial, que compreende a atualidade da revisão teórica da TBS, ainda por se fazer.

A noção de quase-bloco foi apresentada no ano letivo francês de 2013-2014. Vejamos como Carel explica a nova concepção de quasebloco da clássica palavra prudente:

Retomemos o eterno exemplo de "prudente": sua argumentação interna apresentava PERIGO DC PRECAUÇÃO, e sua argumentação externa apresentava os dois aspectos conversos PRUDENTE DC SEGURANÇA e PRUDENTE PT NEG-SEGURANÇA. Nós mantemos 
a hipótese de que a significação de "prudente" contém o aspecto PERIGO DC PRECAUÇÃO. Por outro lado, ao contrário, nós afirmamos agora que ele não contém nenhum dos dois aspectos PRUDENTE DC SEGURANÇA e PRUDENTE PT NEG-SEGURANÇA. O que ele comporta é a alternativa destes dois aspectos, e não estes dois aspectos (CAREL, MACHADO, 2016, p. 5).

Essa nova ideia de que uma palavra comporta "a alternativa de dois aspectos, e não um dos dois aspectos" é mais visível em discursos polêmicos, como por exemplo:

(6) Recebi uma boa quantia de dinheiro este mês.

que pode, no mesmo enunciado, ser encadeado com o segmento "portanto vou gastar" ou com o segmento "no entanto não vou gastar, vou guardar na poupança". O exemplo é dado por nós, mas pela percepção nova de Carel e Ducrot, a palavra plena dinheiro expressaria então um quasebloco, algo como: [DINHEIRO DC GASTAR + DINHEIRO PT NEGGASTAR].

Até então, esta possibilidade não existia na TBS, e o semanticista devia efetivar sua interpretação em uma das duas direções: ou normativa, ou transgressiva. Conforme Carel e Ducrot (2013; 2015), agora, o conteúdo intermediário adentra a teoria por meio do conceito técnico de quase-bloco, que prevê não mais a exatidão [X DC Y] ou [X PT NEG-Y], mas o entremeio da alternativa [X DC Y + X PT NEG-Y] para descrever as significâncias da língua e sua enunciação.

Neste caso acima, alguém que tenha dinheiro, endividado ou não, rico ou não, precisando ou não, bom administrador ou mau administrador, consequente ou inconsequente, e etc, pode compreendê-lo nas duas direções: ter dinheiro significa ter duas alternativas contrárias: gastá-lo e guardá-lo. A revisão teórica da noção de bloco prevê que a transgressividade adentra a normatividade, por vias da neo noção de quase-bloco.

Dentre vários enunciados-exemplos iniciais, os linguistas vão observar que, também em frases interrogativas, a significância da indecisão de uma resposta exata pode expressar-se por vias de um quase-bloco, como, por exemplo, na palavra "dramático", enunciada interrogativamente em: 
(7) Maria e Pedro acabaram de se sentar quando iniciou ofilme. Uma história assustadoramente triste, tal como Bambi, onde a mãe se sacrifica. Era de fato dramático: ${ }^{6}$ será que ele choraria?

Carel e Ducrot (2013, p. 7) afirmam que o sentido de "dramático" ali é um quase-bloco de duas possibilidades, postas pela dúvida:

A expressão-tipo ‘dramático’ não é ambígua. A significação linguística de 'dramático' não contém os dois aspectos [NEG-TRISTEZA DC NEG-EMOCIONADO] e [NEGTRISTEZA PT EMOCIONADO]: ela contém a alternativa destes dois aspectos, que nós chamaremos de 'quase-bloco' de seus dois aspectos (CAREL e DUCROT, 2013, p.7).

2013):

A notação do quase-bloco passa a ser (CAREL e DUCROT,

I) Quase-bloco converso

[A DC C + A PT NEG-C] notado: "A (C)";

II) Quase-bloco transposto

[NEG-A PT C + A DC C] notado: “(A) C”.

Acima, o "A" representa o aporte e o "C" seu suporte, e os parênteses "( )" representam o segmento sobre o qual recai a afirmação + negação, própria do quase-bloco.

Assim, a TBS prevê agora, a partir da revisão bloco/quase-bloco, três procedimentos de análise: [DC], [PT] e [DC + PT], que podem melhor ser aprofundados, por exemplo, em nossas discussões sobre o quase-bloco estrutural e o quase-bloco contextual (CAREL; MACHADO, 2016), oriundas de Carel e Ducrot (2013, p. 14), além de mais dois tipos de quase-blocos, por nós propostos.

\footnotetext{
$\overline{{ }^{6} \text { A palavra francesa }}<$ bébête $>$, tal como a apresentam Carel e Ducrot $(2013$, p. 7), parece não encontrar uma equivalente exata no português que lhe corresponda. Assim, optamos aqui pelo uso da palavra "dramático", valendo-se do contexto do exemplo proposto.
} 


\subsection{Do paradoxo de oposição ao paradoxo de complementação}

Uma outra revisão de forte impacto para a TBS, que ressignifica seu arcabouço teórico consideravelmente, é a da noção de paradoxo.

Se a postura da TBS é estabelecer que a teoria é submissa à significância, e não que a significância é submissa à teoria, qualquer semanticista, inclusive a própria Carel (2011a, p. 29), irá concordar que é muito razoável que alguém instaure o caos nessa disposição elementar do quadrado argumentativo e enuncie:

(8a) Se Pedro está diante de algo perigoso por fazer, ele renunciará a fazê-lo.

(8b) Se Pedro está diante de algo perigoso por fazer, ele se precipitará por fazê-lo.

Qual seria a diferença entre os dois? Para responder, passemos a parafraseá-los por encadeamentos em portanto, para podermos exprimir seus aspectos:

(8a') Pedro está diante do perigo, portanto desistirá.

(8b’) Pedro está diante do perigo, portanto não desistirá.

Como explicar tal distinção de sentido já que não falamos mais da relação portanto/no entanto, mas da nova relação portanto/portanto?

A discussão deste fenômeno foi tratada na Semântica Argumentativa em dois momentos: uma primeira elaboração em textos como Carel e Ducrot (1999a; 1999b; 2005, 2008), e Carel (2011a), de um lado; e uma segunda re-elaboração mais recente, em textos como Carel (2013), de outro lado. Assim, temos um paradoxo na fase de consolidação teórica (de oposição entre doxa e paradoxo) e um paradoxo na fase de revisão teórica (de união entre doxa e paradoxo). Passemos a abordá-los.

\subsubsection{O paradoxo na fase de consolidação: oposição entre doxal/paradoxal}

Na primeira elaboração, Carel e Ducrot (1999a; 1999b) vão explicar que os enunciados acima (8a) (8b) são "blocos contrários". Os dois enunciados não pertencem ao mesmo bloco: um sentido prevê a desistência diante do perigo (8a': Pedro está diante do perigo, portanto desistirá); e o outro prevê a não-desistência diante do perigo (8b': Pedro 
está diante do perigo, portanto não desistirá). Poderíamos dizer que o encadeamento do primeiro (8a) advém do bloco de prudente, e que o encadeamento do segundo (8b) advém do bloco de audacioso. São, assim, dois blocos distintos.

Não se trata de transgressão (no entanto) em nenhum dos casos. Até porque se quiséssemos transgredir os encadeamentos acima, teríamos os co-relativos:

(8a"): Pedro está diante do perigo, no entanto, não desistirá.

(um prudente que agiria de modo audacioso).

(8b"): Pedro está diante do perigo, no entanto desistirá.

(um audacioso que agiria de modo prudente).

Podemos, isso sim, dispor os dois blocos ladeados:

(8a'): [PERIGO DC DESISTIR] e [PERIGO PT NEG-DESISTIR];

e

(8b'): [PERIGO DC NEG-DESISTIR] e [PERIGO PT DESISTIR].

Reflitamos na estranheza desses dois blocos: numa apreciação mais filosófica ou social - que prefacia a apreciação linguística - observase que é mais "óbvio", mais aceito socialmente, que diante do perigo alguém o evite (8a'): evitam-se assaltos, ruas perigosas, viagens com altos índices de ocorrências policiais, compras em sites suspeitos etc. Mas não podemos obrigar uma lucidez unilateral universal, e devemos reconhecer que, da mesma maneira, mesmo que menos óbvio ou menos aceito socialmente, há quem goste, aprecie, busque, enfrente, propague e habite com o perigo de toda ordem ( $8 b^{\prime}$ '), como os masoquistas, andarilhos, loucos, revoltados, depressivos, aventureiros etc. Além de uma gama de pensadores que irão afirmar a contra-doxa ao dizer que viver já é estar em perigo, por si só, porque a segurança é imaginária, e o acaso não é previsível.

Focando essas ideias num prisma mais linguístico, mas nem por isso dispensando a reflexão filosófica e social que integra as significações e sentidos, Carel e Ducrot (2008, p. 11) propuseram tratar desta relação de significâncias "mais óbvias/menos óbvias" respectivamente como bloco doxal e bloco paradoxal. Assim, nomearam o primeiro bloco (8a'): 
[PERIGO DC DESISTIR] de doxal, e o segundo bloco (8b'): [PERIGO DC NEG-DESISTIR] de paradoxal. Linguisticamente falando, um bloco paradoxal trata de contradizer um bloco anterior doxal - conforme a primeira fase de consolidação. Vejamos esta relação proposta por Carel e Ducrot (2008, p. 11):

FIGURA 1 - Esquema da primeira elaboração doxal/paradoxal em oposição, conforme Carel e Ducrot (2008, p. 11)

(8a) DOXAL: “prudente” [PERIGO DC DESISTIR]

medroso

NEG-A PT B imprudente

A PT NEG-B

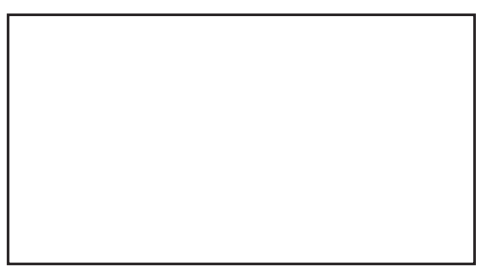

A DC B

prudente
NEG-A DC NEG-B

não-medroso

(8b) PARADOXAL: “audacioso"[PERIGO DC NEG-DESISTIR] covarde
NEG-A PT NEG-B
A PT B

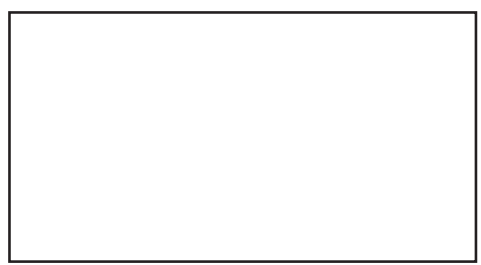
A DC NEG-B
NEG-A DC B audacioso

Legenda do quadro:

A - perigo; B - desistir 
Em suma, na fase de consolidação teórica, o paradoxo é uma noção relacional entre blocos ("8a versus 8b"), não uma relação dentro do mesmo bloco ("portanto versus no entanto", dentre outras). Trata-se, então, apenas de um sentido relacional, isto é, o paradoxal só existe em co-relação com o doxal. Nesta fase, localiza-se um bloco paradoxal para Carel se se localiza um bloco doxal, que lhe opõe.

\subsubsection{O paradoxo na fase de revisão: prolongamento entre doxal/paradoxal}

Contudo, Carel atentou-se para um outro sentido produzido por pares doxais/paradoxais. Tomemos por base o recorte reproduzido abaixo, que trata da adaptação de André Maurois do poema "If", de Kipling, utilizado por Carel (2013, p. 3):

(9) Se você pode ser duro sem jamais ficar com raiva, Se você pode ser bravo e jamais imprudente, Se você sabe ser bom, se você sabe ser sábio, sem ser moral nem pedante

Esta disposição foi negritada por nós desta maneira justamente para ilustrar o procedimento utilizado por Carel para analisar tal trecho de modo pareado: "duro/com raiva"; "bravo/imprudente"; "bom, sábio/ moral, pedante". No excerto acima, Carel vai pontuar que as palavras em negrito são respectivamente doxais (as primeiras) e paradoxais (as segundas). O problema é que ela observa que estes pares não estão em oposição, e sim em prolongamento. Ali, a linguista quer chamar atenção para o fato de que não há uma relação de oposição entre cada par, nem transposição (antiga elaboração); mas uma relação de parentesco e gradualidade entre os pares (nova elaboração).

Dos quatro versos, vejamos os dois primeiros, suficientes para esboçar nossos propósitos aqui. Comecemos pelo primeiro par, "duro/ com raiva". Na enunciação específica deste par, Carel explica que duro é algo necessário e deve ser praticado se colocado na relação de comparação com raivoso, que é um excesso de duro e deve ser evitado. E é a relação mesma entre os dois termos que torna exprimível seus aspectos: "O emprego de duro tem como sentido o aspecto transgressivo [A FAZ SOFRER PT X FAZ A], inscrito na própria significação do adjetivo duro, e esse aspecto substitui o aspecto [A FAZ SOFRER DC X FAZ A] significado por raivoso" (CAREL, 2013, p. 8). 
Carel vai atentar-se para dois fatos da particularidade da relação entre estes dois aspectos, duro = [A FAZ SOFRER PT X FAZ A] e raivoso $=$ [A FAZ SOFRER DC X FAZ A]: trata-se da já conhecida disposição de doxal/paradoxal, como se vê bem nestes aspectos (mantêm-se as palavras e mudam-se apenas os conectores DC e PT). A novidade é que se constata que também se trata de uma relação de gradualidade, própria dos transpostos. Para confirmar isso, ela propõe uma averiguação pela aplicação de até mesmo, próprio para esta função de gradualidade dos transpostos, assim: "ele era duro, e até mesmo raivoso".

A grande novidade é que a relação de gradualidade até então só se via em aspectos doxais, jamais entre um doxal e um paradoxal, dados como oposições. Temos aqui um nó teórico: a gradualidade é do âmbito do bloco doxal. Falar em gradualidade entre doxo e paradoxo não é (era) teoricamente permitido na primeira fase de consolidação teórica. Mas nesta fase de revisão, o que se vê aqui é que o sentido afronta e abala a disposição teórica doxal versus paradoxal, e há algo ali de gradual sem ser uma relação transposta (já que a relação transposta é vista entre os aspectos doxais, e aqui teríamos uma relação entre um doxal e um paradoxal): "há entre duro e raivoso uma relação gradual (ele era duro, e até mesmo raivoso), sem que esses termos exprimam aspectos transpostos" (CAREL, 2013, p. 7).

Apenas este verso leva Carel $(2013$, p. 9) a refletir neste nó teórico: "Ora, aí está o coração de nosso problema, os dois aspectos [A FAZ SOFRER PT X FAZ A] e [A FAZ SOFRER DC X FAZ A] significados por duro e raivoso não são transpostos. Como, então, dar conta do que Maurois adverte como sendo um excesso?"

Deste primeiro verso do trecho, Carel $(2013$, p. 10) reterá a fórmula: "se você pode ser $X$ sem jamais ser $Y$ " como própria de uma nova relação gradual entre aspectos doxais-paradoxais.

Avancemos o par "bravo/imprudente". Tomemos a argumentação interna estrutural de prudente para poder falar de imprudente: conforme Carel e Ducrot (2008, p. 11), prudente expressa [PERIGO DC NEGFAZ]. Neste caso específico do poema, sua transgressão [PERIGO PT FAZ] será atribuída a bravo, e o aspecto de imprudente será seu sentido contextual, o paradoxo [PERIGO DC FAZ]. Ela assume a nova relação de prolongamento do paradoxo: "É forçoso admitir que há certo parentesco entre a significação literal de imprudente [PERIGO PT FAZ] e seu sentido contextual no poema de Maurois [PERIGO DC FAZ]" (CAREL, 2013, p. 11). 
É preciso por em relação o aspecto contextual de imprudente [PERIGO DC FAZ], com o aspecto de bravo [PERIGO PT FAZ] para explicitar/explicar o sentido do verso "Se você pode ser bravo e jamais imprudente". Nesse sentido, Carel vai explicar que a fórmula "se você pode ser X sem jamais ser Y", do primeiro verso, é assimilada à fórmula "se você pode ser X e jamais $Y$ " do segundo verso. Diante do nó teórico do primeiro e segundo versos que explicitam um elo semântico entre doxal e paradoxal, Nesta fase de revisão, Carel assume essa estranha, mas possível gradualidade:

O estudo da gradualidade subjacente aos dois primeiros versos do poema que escolhemos vai nos levar à questão do paradoxo e de seu elo semântico com a doxa. [...] O paradoxo aparecerá, assim, não como um reflexo inverso da doxa, mas como um prolongamento dessa última, seu complemento no interior de um mesmo bloco semântico (CAREL, 2013, p. 7, grifo nosso).

Como consequência deste modo de entender doxa e paradoxo, há uma outra descoberta apresentada por Carel: além dos três modos básicos e formais da construção textual (conversos, transpostos e recíprocos), Carel apresentará um novo (ou pelo menos neste momento, dado como novo): a gradualidade entre doxo e paradoxo, significação ou sentido oriundo da relação doxal/paradoxal pensada não enquanto oposição, mas enquanto prolongamento. Nesta fase de revisão da TBS, doxal e paradoxal não são mais dois blocos em oposição. É um só bloco. O paradoxal é um prolongamento do doxal.

A re-elaboração da relação doxal/paradoxal é resumidamente a seguinte: o que antes se entendia por [4 aspectos] versus [4 aspectos] agora é pensada como [8 aspectos]. Não se trata mais, portanto, de dois blocos distintos em espelho, mas de um mesmo e único bloco: doxal e paradoxal "[...] compartilham igualmente alguma coisa: seus próprios conteúdos são aparentados" (CAREL, 2013, p. 1).

Diante disso, uma questão passa a afrontar o engendramento analítico da TBS, a funcionalidade do quadrado argumentativo. Isto é, a grande questão passa a ser: como representar, agora, 8 aspectos (fase da revisão) em um quadrado argumentativo que vislumbrava só 4 aspectos (fase da consolidação)? Carel coloca devidamente a necessidade de uma reconfiguração teórica capaz de tratar o paradoxo: 
É preciso, portanto, repensar uma decisão teórica que me parecia evidente, aquela que impunha a cada bloco ser ou doxal, ou paradoxal. Isto é, não conter nunca, ao mesmo tempo, um aspecto de um tipo e um aspecto do outro. Esse questionamento leva a modificar o número que eu atribuía, até aqui, aos blocos semânticos, que podem, doravante, ser apreendidos não por quatro, mas por oito aspectos. Na sequência dessa remodelação, pelo menos dois problemas teóricos se colocam, os quais eu me contento em indicar aqui. De um lado, deve-se afirmar que todos os blocos contêm ao mesmo tempo um aspecto $\mathrm{A}$ DC B e um aspecto A DC NEG B. Dever-se-ia, portanto, abandonar completamente a visão quadripartida dos blocos semânticos, ou é preciso mantê-la parcialmente? De outro lado, quais são as relações que estruturam os blocos em oito aspectos? Será necessário ir além das três relações fundamentais (reciprocidade, conversão e transposição) (CAREL, 2013, p. 15, grifos nossos).

\section{Do quadrado argumentativo ao cubo argumentativo}

A questão acima reclama pesquisas dos semanticistas da TBS, e atualmente ainda não foi respondida por Carel ou Ducrot, de modo direto. ${ }^{7}$ A sugestão apresentada aqui - enquanto hipótese, ainda - é oriunda de nosso trabalho (MACHADO, 2015). ${ }^{8} \mathrm{Na}$ falta de uma disposição melhor, temos sugerido, nesta nova linha de concepção doxa/paradoxo em prolongamento, o cubo argumentativo:

\footnotetext{
${ }^{7}$ Já existem textos sobre tais questões, mas ainda não publicados. É esperado, no Brasil, um livro a ser lançado por volta de 2017 ou 2018, sobre as revisões da TBS quanto ao quase-bloco, quanto ao modo de pensar os 8 aspectos doxais-paradoxais em prolongamento, e quanto à pressuposição, dentre outras revisões.

${ }^{8}$ Queremos registrar aqui nossa gratidão à fundadora da TBS, Marion Carel, por nos escutar, discutir, debater e opinar pessoalmente conosco sobre esta hipótese do cubo argumentativo e os novos quase-blocos que propomos.
} 
FIGURA 2 - Cubo argumentativo: único bloco de 8 aspectos doxais-paradoxais.

Esquema da segunda elaboração doxal-paradoxal em prolongamento, conforme Machado (2015, p. 180-186).

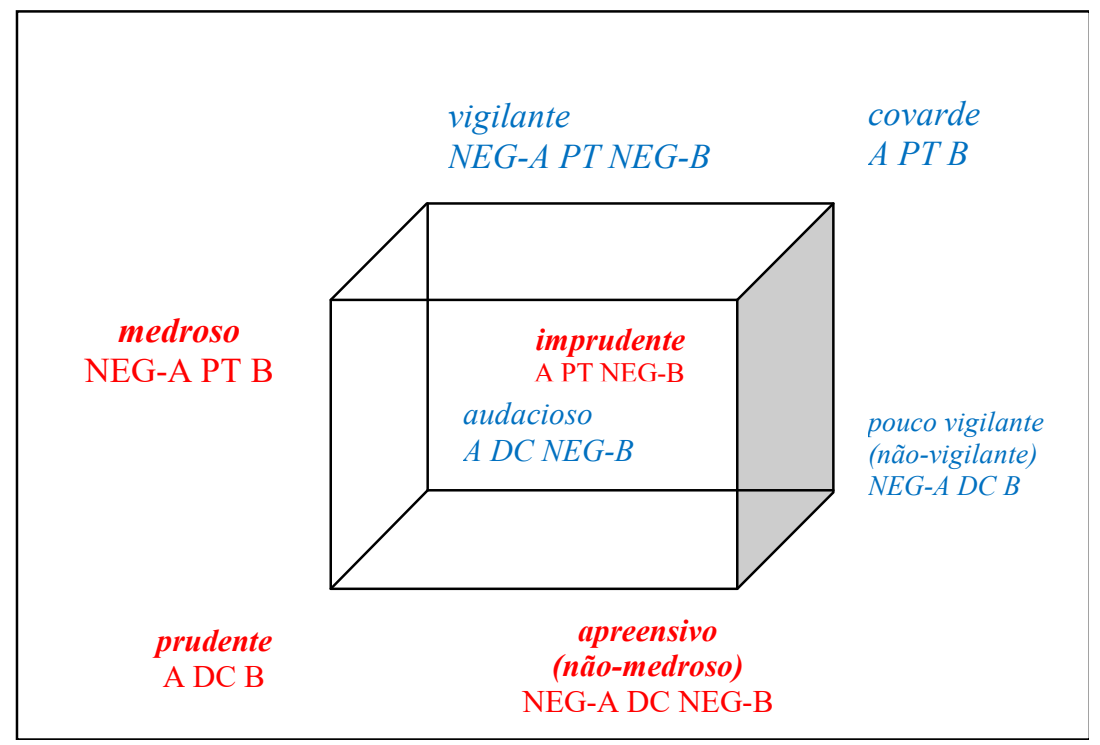

Como temos dito (MACHADO, 2015, p. 180-186), grosso modo, o cubo argumentativo abarcará tudo que o quadrado argumentativo já prevê (as muitas relações discursivas embasadas nos movimentos converso, transposto e recíproco), próprias dos aspectos doxais, que colocaremos na face frontal do cubo, somando a elas mais quatro outros aspectos paradoxais, que colocaremos na face secundária do cubo. Da relação entre face frontal e final, localizar-se-á a neo-relação de gradualidade doxa/paradoxo.

Fazer semântica pelo trabalho teórico-ortogonal parece ser uma resposta razoável às indagações careleanas, sem ter que abandonar o quadrado argumentativo, e enriquecendo-o e adequando-o às novas necessidades, quando elas se fizerem presentes.

Ao repensar o sentido de um enunciado no cubo argumentativo, visualiza-se amplamente a disposição relacional semântica: em arestas (retas: conversos, transpostos, recíprocos, e agora a gradualidade doxal/ paradoxal); vértices (duas retas de encontro: um aspectos ligados a dois ou mais enunciados, por exemplo) ; em planos (faces: doxal, paradoxal, e suas combinações); a isometria (outras figuras delineadas no cubo: por 
exemplo, o tratamento de questões textuais, que exigirão a análise do concatenamento de muitos enunciados ou parágrafos); e tudo mais que as projeções ortogonais nos permitir.

O cubo parece ser um lugar privilegiado para se observar arranjos combinatórios de aspectos infindos, expondo e sugerindo relações das mais variadas, e por isso explorando melhor os formatos que um sentido possa ter. $\mathrm{O}$ que tão somente faremos é apenas mostrar uma parca movimentação relacional deste cubo com intuito de visualizar o paradoxo semântico.

Tomemos, então, o cubo argumentativo para testá-lo. Na esteira da fórmula "se você pode ser X e jamais $Y$ ", que expressaria a gradação descoberta por Carel, nós proporemos a fórmula "se você pode ser $X$ mesmo sendo $Y$ ", 9 que expressaria um paradoxo semântico entre aspectos da face frontal-doxal e final-paradoxal do cubo argumentativo. Para tal, retomemos e atualizemos os dois quadrados argumentativos da elaboração doxal/paradoxal, agora atualizado pelo cubo argumentativo, acima, e vamos explorar as relações que façam interagir as faces doxais e paradoxais do cubo.

A partir do cubo, diremos que Carel (2013) vislumbrou uma gradação do tipo converso entre as faces doxal-paradoxal. Manter-nosemos ainda nesta reta conversa. Ainda pelo movimento converso entre os planos da face frontal-doxal/final-paradoxal do cubo argumentativo, proporemos aqui não mais uma gradualidade, mas um paradoxo semântico, ${ }^{10}$ resultado da fórmula: se você pode ser $X$ mesmo sendo $Y$. Teríamos:

(10) Se você pode ser audacioso, mesmo sendo imprudente.

Se você pode ser prudente, mesmo sendo covarde.

Se você pode ser pouco vigilante, mesmo sendo medroso

Se você pode ser vigilante, mesmo sendo apreensivo.

\footnotetext{
9 Também agradecemos a rica discussão com a professora Marion Carel neste ponto, que nos levou a entender a profundidade das espessuras significantes dos "limite das significações" a partir do pensamento em oito aspectos.

${ }^{10}$ Paradoxo semântico não se trata da relação doxal-paradoxal. Por este termo entendemos significações paradoxais do senso comum, como: morto-vivo, sigilo relativo, bonito feio, pobre rico etc.
} 
A hipótese é observar que esta fórmula (se você pode ser Xmesmo sendo $Y$ ) faz ver a significação de um paradoxo semântico por meio da relação ortogonal conversa entre as faces doxais/paradoxais do cubo argumentativo. Em outras palavras, a fórmula "se você pode ser X mesmo sendo $Y$ " faz ver um novo quase bloco do tipo [A (DC) B], próprio da inseparabilidade entre aspectos frontais-doxais e finais-paradoxais do mesmo cubo argumentativo. Dito por um modo metateórico, temos aqui um quase-bloco converso entre as faces doxal e paradoxal do mesmo cubo argumentativo:

QUADRO 1 - o novo quase-bloco converso entre as faces doxal/paradoxal do tipo [A (DC) B] (MACHADO, 2015, p. 184-185).

\begin{tabular}{|c|c|}
\hline $\begin{array}{l}\text { Se você pode ser audacioso, mesmo sendo imprudente } \\
\text { [A DC NEG-B] }+{ }^{+}+\text {A PT NEG-B] } \\
\text { [A (DC) NEG-B] }\end{array}$ & $=$ \\
\hline 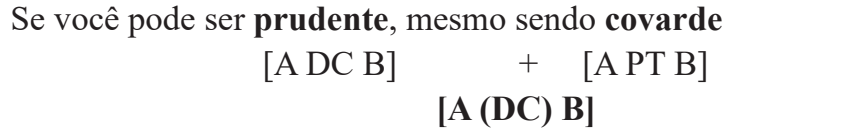 & $=$ \\
\hline $\begin{array}{l}\text { Se você pode ser pouco vigilante, mesmo sendo medroso } \\
\text { [NEG-A DC B] + }+[\text { NEG-A PT B] } \\
{[\text { [NEG-A (DC) B] }}\end{array}$ & $=$ \\
\hline $\begin{array}{l}\text { Se você pode ser vigilante, mesmo sendo apreensivo } \\
\text { [NEG-A PT NEG-B] }+[\text { NEG-A DC NEG-B }] \\
{[\text { [NEG-A (DC) NEG-B] }}\end{array}$ & $=$ \\
\hline
\end{tabular}

Uma questão interessante que surge é que não podemos mais tratar estas unificações por meio do quase-bloco doxal, já que o quasebloco doxal é uma possibilidade apenas da face frontal-doxal (nos tipos quase-blocos transpostos e quase-blocos conversos, da primeira fase, que opõe doxal/paradoxal). Não havia ainda, antes de nossos estudos, um quase-bloco que unisse as faces doxal-paradoxal. Assim, o que proporemos, momentaneamente, é tratar desta nova relação de quase-bloco entre a face frontal-doxal/final-paradoxal, pela notação de parêntese "no" conectivo. Assim: [PERIGO (DC) NEG-DESISTIR], onde, conforme o quadro acima, o (DC) significaria a dupla alternativa: [PERIGO (DC+PT) NEG-DESISTIR]. 
Outras tantas relações podem ser exploradas no cubo argumentativo. Ficará por se pesquisar as muitas riquezas de relações deste cubo, dentre elas as relações de plano: face frontal/final; frontal/ lateral esquerda; frontal/lateral direita; lateral esquerda /final; lateral direita final; superior/inferior; superior/lateral esquerda; superior/lateral direita; inferior/lateral esquerda; inferior/lateral direita; inferior/frontal; pelo menos.

\section{Considerações Finais}

Não quisemos, ao fracionar o histórico da TBS em duas décadas, estabelecer um "calendário de mundanças", mas pensar em um "processo de evolução teórica" e suas significações, balizados em duas determinações que lhe constitui: seu início de consolidação enquanto teoria, e sua atualidade de revisão contínua. Em outras palavras, no histórico dos quase 50 anos de Semântica Argumentativa - que não trabalhamos aqui -, quisemos atentar para o fato de que revisar significa, antes, aprofundar do que trocar ou abandonar conceitos. Assim, vimos que quando se prefere certas formulações a outras (como ao se afastar de escalas e topoï, mais anteriormente, e afastar-se do enunciador e paradoxocontrário, mais atualmente), quando se prefere certas formulações a outras, a TBS está antes aprofundando conceitos técnicos e exigindo-lhes maior compatibilidade quanto aos critérios epistemológicos constituídos pelos fatores que o determinam (e determinam tanto a Linguística como o que a TBS pensa ser um Estruturalismo). O que, consequentemente, dá rigor operacional para as análises deste quadro teórico.

Assim, queremos condensar algumas conclusões principais que ressignificam a totalidade da leitura da bibliografia teórica da TBS que fizemos aqui:

a) O histórico processual das reformulações da TBS nos últimos anos significa que não se elege novos conceitos: aprofunda-se e ressignifica-se os antigos. Nossa hipótese basilar desenvolvida aqui foi que se deve estudar a TBS enquanto uma teoria única com quase meio século de idade ${ }^{11}$

\footnotetext{
${ }^{11}$ Neste sentido, queremos agradecer as discussões valiosas que tivemos com uma das maiores pensadoras da TBS na América Latina, a professora Leci Borges Barbisan.
} 
b) Na esteira desta consideração, é preciso desconstruir uma leitura fragmentada que apresenta a TBS como uma teoria inédita dos anos 90. O leitor atento da vasta bibliografia da Semântica Argumentativa sabe que não se trata de uma teoria nova: a TBS é antes o aprofundamento e radicalização de uma teoria anterior, de quase cinco décadas, disposta agora em moldes mais formalizados que lhe dão rigor e amplitude de análise, precisamente em DC e PT.

c) Devido à sua natureza enunciativa e discursiva, que busca investigar a significação por vias da enunciação, com toda sua riqueza, não é produtivo filiar a TBS em nomenclaturas que lhe empobreceme rotulam seu postulado, pois a TBS opera por um Estruturalismo Enunciativo: mantém o foco e está aberta a questões refinadas, contemporâneas, textuais, paradoxais e etc, como se viu pelo quase-bloco, mesmo que o faça por vias saussureanas estruturais.

d) A TBS é ainda uma teoria em desenvolvimento, não importa a maturidade de suas décadas. O que demanda leituras e críticas cuidadosas em todos os sentidos, além da leitura do acervo integral da teoria para tal. Seus elaboradores, sobretudo Carel e Ducrot, ainda trabalham continuamente no intuito de desenvolver, com afinco, rigor e cientificidade, uma teoria de base argumentativa na língua, por uma postura metodológica enunciativa e saussureana.

\section{Agradecimento}

Sou grato pelo financiamento de minha estada na França para frequentar reuniões, aulas, apresentações, grupos de pesquisa e seminários em Paris, sobretudo os de Oswald Ducrot e Marion Carel. Sem este financiamento não seria possível mobilizar o acervo da TBS em dois países para efetivar esta pesquisa. Registro minha gratidão às minhas entidades financiadoras: CAPES-PDSE, FAPEMIG, SRE-MG e PAEx-UEMG. 


\section{Referências}

BALLY, Charles; SECHEHAYE, Albert. Cours de linguistique générale. Paris: Payot, 1985.

BOUQUET, Simon; ENGLER, Rudolf. Ecrits de linguistique générale. Paris: Gallimard, 2002.

CAREL, Marion. Vers une formalisation de la théorie de l'argumentation dans la langue. 1992. Thèse (Doctorat en Mathématiques et Applications aux Sciences de l'Homme - Logique linguistique) - École des Hautes Études en Sciences Sociales (EHESS), Paris, 1992.

CAREL, Marion. Introduction. In: CAREL, Marion. Argumentation et Polyphonie: de Saint-Augustin à Robet-Grillet. Paris: Harmattan, 2009.

CAREL, Marion. L'entrelacement argumentatif: lexique, discours et blocs sémantiques. Paris: Honoré Champion, 2011a.

CAREL, Marion. Análise semântica e análise textual. Trad. Telisa Furlanetto Graeff. Revista do Programa de Pós-Graduação em Letras da Universidade de Passo Fundo, v. 7, n. 2, p. 184-197, 2011 b.

CAREL, Marion. Tu seras un homme, mon fils. Un prologement de la doxa: le paradoxe, 2013. [Inédito]

CAREL, Marion. Présupposition et organisation du sens, 2016. [Inédito] CAREL, Marion; DUCROT, Oswald. Le problème du paradoxe dans une sémantique argumentative. Langue Française, Paris, v. 123, p. 6-26, 1999a. https://doi.org/10.3406/lfr.1999.6293.

CAREL, Marion; DUCROT, Oswald. Les propriétés linguistiques du paradoxe: paradoxe et négation. Langue Française, Paris, v. 123, p. 27-40, 1999b. https://doi.org/10.3406/lfr.1999.6294.

CAREL, Marion; DUCROT, Oswald. La semántica argumentativa: una introducción a la teoría de los bloques semánticos. Buenos Aires: Colihue, 2005.

CAREL, Marion; DUCROT, Oswald. Descrição argumentativa e descrição polifônica: o caso da negação. Trad. Leci Borges Barbisan. Letras de Hoje, Porto Alegre, PUC, v. 43, n. 1, p. 7-18, 2008. 
CAREL, Marion; DUCROT, Oswald. Atualização da polifonia. Trad. Leci Borges Barbisan. Desenredo, Passo Fundo, v.6, n. 1, p. 9-21, 2010. CAREL, Marion. DUCROT, Oswald. Temporalité, argumentation et récit, 2013. [Inédito]

CAREL, Marion; DUCROT, Oswald. Pour une analyse argumentative globale du sens. Arena Romanistica, Bergen, v. 1, p. 72-89, 2014.

CAREL, Marion; DUCROT, Oswald. Langage poétique et discours engagé, 2015. [Inédito].

CAREL, Marion; MACHADO, Julio Cesar. Debate sobre a Teoria dos Blocos Semânticos e a Semântica do Acontecimento. Letras de Hoje, Porto Alegre, v. 51, n. 1, p. 38-46, 2016. https://doi.org/10.15448/19847726.2016.1.21363.

DUCROT, Oswald. Dire et ne pas dire. Principes de sémantique linguistique. Paris: Hermann, 1972.

DUCROT, Oswald. Le dire et le dit. Paris: Les Éditions de Minuit, 1984.

DUCROT, Oswald. Argumentação retórica e argumentação linguística. Letras de Hoje, Porto Alegre, v. 44, p. 20-25, 2009.

MACHADO, Julio Cesar. O paradoxo a partir da Teoria dos Blocos Semânticos: língua, dicionário e história, 2015. 373f. Tese (Doutorado em Linguística) - Universidade Federal de São Carlos - PPGL / UFSCar, São Carlos-SP, 2015. 